\title{
Non-Cardiac Chest Pain
}

National Cancer Institute

\section{Source}

National Cancer Institute. Non-Cardiac Chest Pain. NCI Thesaurus. Code C78504.

Pain in the chest unrelated to a heart disorder. 